TP Periodica Polytechnica

Mechanical Engineering

60(3), pp. 185-192, 2016

DOI: 10.3311/PPme.9041

Creative Commons Attribution (i)

RESEARCH ARTICLE

\section{Modification of a Steam Valve Diffuser for Enhanced Full Load and Part Load Operation Using Numerical Methods}

\author{
Clemens Bernhard Domnick ${ }^{1 *}$, Friedrich-Karl Bera ${ }^{1}$, Dieter Brillert ${ }^{1}$, \\ Christian Musch ${ }^{2}$
}

Received 22 January 2016; accepted after revision 03 March 2016

\begin{abstract}
The flow in a steam turbine inlet valve is investigated and improved by numerical methods. From the fluid dynamic point of view two requirements exist: Low pressure losses are desired at the fully opened valve position and dynamic fluid forces acting on the valve plug should be minimized to reduce valve vibration. Usually these undesired dynamic fluid forces occur when the flow is throttled at part load. It is found that these fluid forces are generated by separated jets in the diffuser. The attachment and the separation of the jet are related to the Coanda effect.

By understanding the flow physics a way is found to modify the diffuser design in such a way that the flow separations are reduced. Bell-shaped diffusers are able to reduce the flow losses at full load operation. A diffuser contour that fulfils both requirements is developed.
\end{abstract}

\section{Keywords}

Coanda effect, diffuser flow, steam turbine valve, supersonic wall jet, CFD, wall jet separation

\footnotetext{
${ }^{1}$ Chair of Turbomachinery, Faculty of Engineering, University of DuisburgEssen, Lotharstrasse 1, 47057 Duisburg, Germany

${ }^{2}$ Siemens Energy Sector, Rheinstrasse 10045478 Muelheim an der Ruhr, Germany
}

*Corresponding author, e-mail: bernhard.domnick@uni-due.de

\section{Introduction}

Steam turbine inlet valves are used to control the power output of steam turbines. The design of the valve has to meet several requirements. One criterion is the pressure loss of the valve in open position. It should be as small as possible, as the pressure loss reduces the efficiency of the steam turbine installation. Another crucial point is the structural integrity of all valve components. If the valve is operated at part load, a large amount of energy bearing the potential for vibrations is dissipated. Some examples show that at such conditions failures of valve components can occur. Tecza et al. [1] and Zhang et al. [2] report of stem fractures. Also surrounding components such as steam pipes can be damaged by valve vibrations. An example for this is given by Michaud et al. [3].

\subsection{Literature review}

Several investigations show, that the most common causes of valve vibrations are oscillating shocks (Pluviose [4]), jet instabilities (Ziada and Bühlmann [5], Nakano et al. [6]) and jet separations (Stastny [7], Morita [8]). High speed jets are generated at throttled operation when small pressure ratios exist and the flow path is constricted between the valve plug and the valve seat. Especially at large pressure differences jets issuing from the gap formed by the seat and the plug have a large kinetic energy that can be converted to acoustic radiation causing vibrations.

Hence, the major objective in the aerodynamic design of a steam valve is avoiding shocks and guiding the jet formed between the valve plug and the valve seat in such a way, that it is kept stable and pressure fluctuations are as small as possible. A comparison of different studies shows that an annular wall jet attached to the valve diffuser is the most desired flow topology in terms of pressure fluctuations and vibrations. Stastny et al. [7] show that the desired annular wall jet topology can be obtained by a suitable design of the valve plug. In this study a valve plug with a flat bottom is compared to a convex valve plug as shown in Fig. 1.

In case of the convex plug, the flow attaches to the plug guiding it into the centre of the valve diffuser, where an undesired, unstable core flow is formed. In case of the sharp edged valve 
plug there is no possibility for the flow to attach to the plug. Hence, the flow remains attached to the valve seat and the subsequent valve diffuser and the desired annular flow is formed. In case of this flow topology the jet is stabilized by the wall and hence the pressure pulsations are reduced significantly.

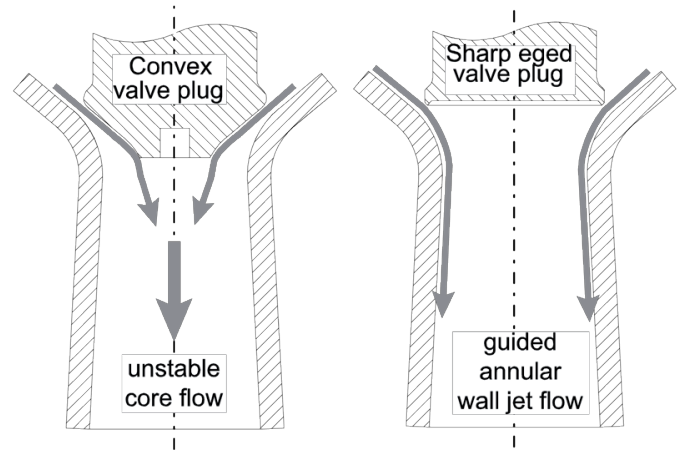

Fig. 1 Valve plug designs. Sketch by the authors according to Stastny [7]

The CFD analyses of Stastny et al. [7], Schramm et al. [9] and Domnick et al. [10] show that steam valves with sharp edged valve plugs provide the desired core flow at wide operation condition but the undesired core flow can still occur at certain operation conditions. These are large valve lifts and small pressure ratios. Domnick et al. [10] additionally reveal that the attachment of the jet to the wall is related to the Coanda effect. Unsteady CFD calculations by Domnick et al. [11] indicate, that the dynamic fluid forces acting on the valve plug are significantly reduced when the jet attaches.

The knowledge obtained from these studies, shows, that the flow instability and the valve vibrations are reduced when the attached annular wall jet exists in the valve diffuser. In this case the jet is stabilized by the wall and the kinetic energy bearing the potential for pressure fluctuations is gradually dissipated at the wall.

In this study the contour of a steam valve diffuser is improved to enhance the attachment and hence reduce the vibrations without increasing the pressure loss at the opened valve position. Preliminary studies are reported by the authors in [12].

\subsection{Design of the valve diffuser}

A characteristic design of a steam valve diffuser as installed in large power stations is examined in this study. When a valve of this design is operated in the admissible range of design mass flow, vibrations can be clearly measured, but the vibrational level does not exceed the acceptable level.

The design of the valve diffuser is shown in Fig. 2. The flow coming from the valve chest (A) is throttled in the valve gap formed by the valve plug (B) and the curved valve seat (C). Directly downstream of the valve seat the valve diffuser (D) is located. The baseline diffuser design shown here is a simple conical diffuser with a constant opening angle.

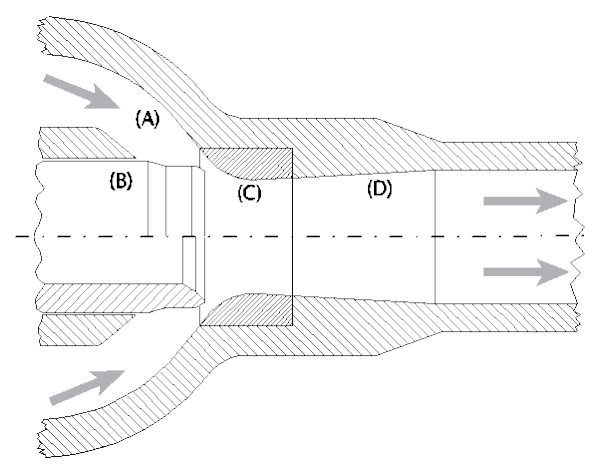

Fig. 2 Design of the baseline diffuser

\subsection{Vibrational characteristic of the valve}

The valve shows a typical vibrational characteristic when it is operated at part load. An example is given in Fig. 3 showing the vibrational acceleration at the valve stem, the pressure ratio and the valve lift. $100 \%$ lift refers to the open position, $0 \%$ valve lift corresponds to the closed valve.

At low valve lifts, a high vibrational level can be seen. If the valve is gradually opened, the pressure increases with increasing valve lift due to the swallowing capacity of the turbine connected to the valve. At a certain point, the vibrations suddenly drop to a significant lower level. The pressure ratio of the valve is defined in Eq. (1).

$$
\pi_{\mathrm{Va}}=\frac{p_{\mathrm{out}}}{p_{\mathrm{t}, \mathrm{in}}}
$$

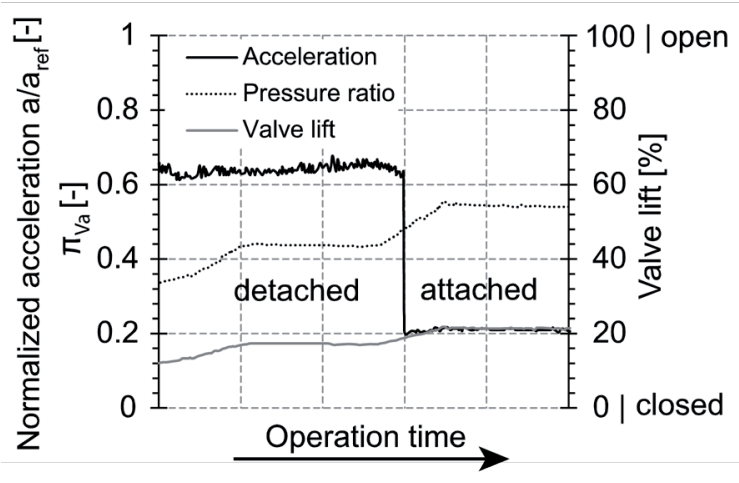

Fig. 3 Operational record of a steam valve

The transition point from high vibrations to low vibrations can be reproduced in a single steam turbine installation, but varies among steam turbine installations with different swallowing capacities. In Domnick et al. [10] it is shown that this phenomenon is related to the attachment of the wall jet.

\section{Numerical set up}

The CFD simulations concerning the wall jet separation and the pressure loss are conducted using the commercial CFD solver Ansys-CFX 14. This code employs a fully coupled implicit Navier-Stokes solver. The transient numerical set up finally chosen is second order accurate in space. The thermodynamic and 
transport properties of the working fluid steam are modeled with the IAPWS real gas model by Wagner et al. [13]. The standard $\mathrm{k}-\omega$-SST-turbulence model by Menter [14] is applied for the steady state CFD calculation. In a comparison to experiments with adverse pressure gradient flow conducted by Menter [14] the $\mathrm{k}-\omega$-SST has a better accuracy than the k- $\varepsilon$ - or the k- $\omega$-turbulence model. Clari [15] shows that CFD calculations using the $\mathrm{k}-\omega$ SST model reproduce the experimentally obtained pressure distribution in a scaled steam valve diffusor. Bianchini et al. [16] use this model for calculating pressure loss in steam valves.

An automatic near wall treatment provided by the flow solver is used to model the flow close to the wall. This treatment blends automatically the wall value for $\omega$ between a wall function for the logarithmic layer and a near wall formulation.

To analyze the jet separations and the pressure loss of the flow in the valve diffuser, the valve is investigated at different lift positions. These are summarized in Table 1. Different flow domains are used for the investigation on the pressure loss and on the wall jet separations. At full valve lift, the geometry of the entire valve diffuser is modeled because asymmetric flow topologies can be relevant to flow separations and hence affect the flow losses. As the flow is not throttled, jet phenomena do not exist at this lift position. The formation of a wall jet is observed at lifts below $70 \%$ lift. For the investigation of the jet flow a segment of the diffuser is sufficient according to a previous investigation of the authors [10].

Table 1 Different model types

\begin{tabular}{lll}
\hline Valve lift & Investigation of & Type of model \\
\hline $100 \%$ & Pressure loss & Full model \\
$20 \%$ & Wall jet separation & Segment \\
$14 \%$ & Wall jet separation & Segment \\
$7 \%$ & Wall jet separation & Segment \\
$2 \%$ & Wall jet separation & Segment \\
\hline
\end{tabular}

As the wall friction strongly impacts the flow losses, special attention is paid for the full model to the resolution of the boundary layer. The $\mathrm{y}^{+}$value is below 10 in the diffuser. As the automatic near wall treatment is used, large parts of the loglaw-region and the buffer region of the boundary are resolved. 40 nodes lie in boundary layer. The near wall velocity profile at the throat of the valve seat is shown in Fig. 4. Each dot demarks a computational node.

Furthermore, the influence of the discretization outside the boundary layers on the results is analyzed. Three different grids are compared with respect to the total pressure loss. The results are summarized in Table 2. The total pressure loss is defined by Eq. (2).

$$
\Delta p_{\mathrm{t}}=p_{\mathrm{t}, \text { in }}-p_{\mathrm{t}, \mathrm{out}}
$$

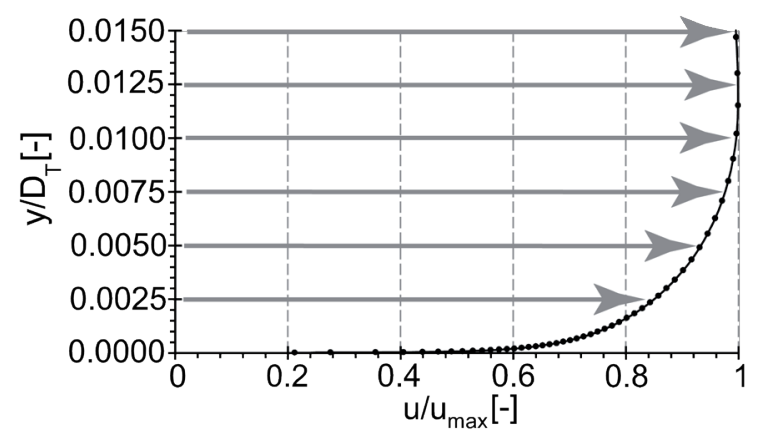

Fig. 4 Boundary layer profile

Table 2 Grid properties

\begin{tabular}{lll}
\hline Grid & Nodes $\times 10^{6}$ & $\Delta p_{\mathrm{t}} / \Delta p_{\mathrm{t}, \max }[-]$ \\
\hline A & 0.59 & 1 \\
B & 0.95 & 0.875 \\
C & 3.9 & 0.885 \\
\hline
\end{tabular}

Grid B is chosen for the calculation. A discretization error of $1.2 \%$ is estimated for the pressure loss using Richardson extrapolation. The computational domain is shown in Fig. 5.



Fig. 5 CFD model for flow loss estimation

In case of throttled flow the investigation is focused on the attachment of the jet. Previous studies conducted by the authors [10] show that attachment characteristics of the wall jet can be obtained by CFD models comprising segments of the axisymmetric diffuser. At typical operation in part load, the flow is chocked and regions with supersonic flow requiring fine block structured hexahedral grids exist. A study on the required spatial resolution for the jet flow can be found in Domnick et al. [10]. The $\mathrm{y}^{+}$-value in the diffuser is below 30 and the boundary layer is resolved by at least 20 nodes.

Due to the large volume upstream of the small cross sectional area where the flow is chocked, the solution converges slowly. Therefore the use of $60^{\circ}$ axisymmetric segments gives a significant reduction of computational time. The flow domain of the $20 \%$ lift case is shown in Fig. 6. 


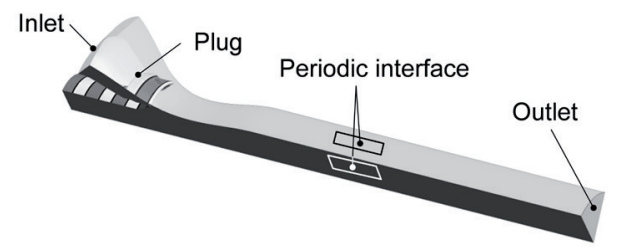

Fig. 6 CFD model for wall jet calculations

\section{Investigation of wall jet separation}

At first the baseline design of the steam valve is analyzed at low valve lifts for which the vibrations related to the wall jet detachment occur. Two basic flow topologies exist: The detached flow and the attached flow which are both shown in Fig. 6. In both cases the jet is supersonic. At higher pressure ratios the wall jet formed by the valve plug and the valve seat is attached. The attached jet depicted in Fig. 7 shows the typical structure of an under expanded supersonic jet comprising expansion and recompression zones (A). With decreasing pressure ratio the strength of the expansion and recompression zones increases. At a certain degree of under expansion an oblique shock (B) occurs downstream the first expansion zone. The flow defection caused by the oblique shock increases with decreasing pressure ratio. When the pressure ratio is sufficiently low, the jet detaches.

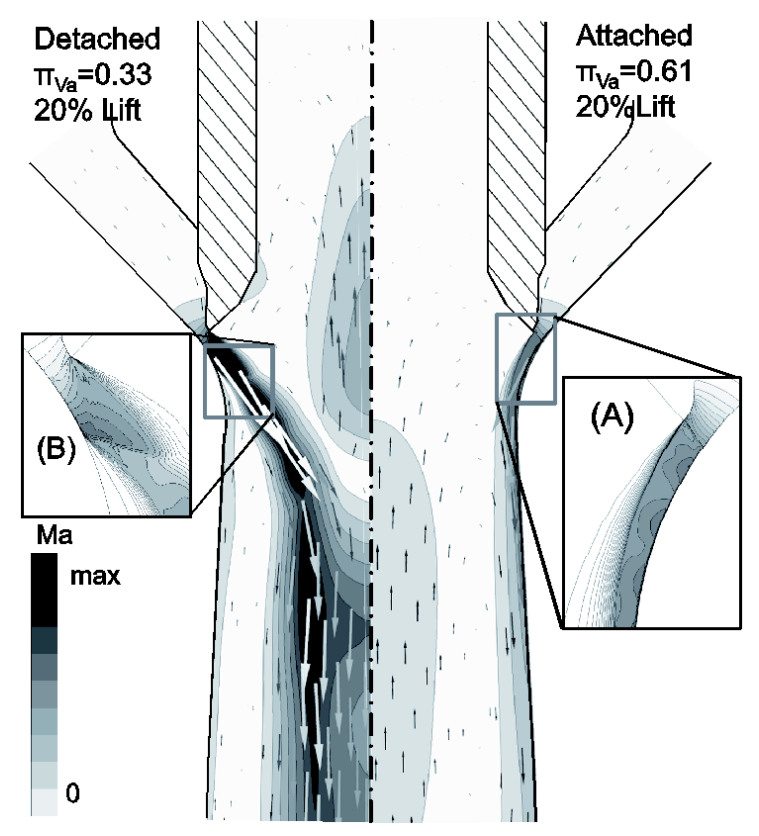

Fig. 7 Flow topology in case of the attached and detached flow topology.

The pressure ratio at which the flow topology changes is determined for different valve lifts by CFD calculations. Therefore, the outlet pressure is changed gradually at a constant valve lift and a constant inlet pressure. Both increased and decreased outlet pressure is used because hysteresis effects exist.
The pressure ratio for which the detached jet attaches is called pressure ratio of attachment, the pressure ratio for which the attached jet detaches is called pressure ratio of detachment. The results are depicted in Fig. 8. The pressure ratios of attachment and detachment increase with increasing valve lift.

To figure out the influence of the geometry on the wall jet separations, the numerical results are compared to experimental studies concerning the separation of under expanded Coanda wall jets. These independent experiments are conducted by Gregory-Smith and Gilchrist [17], Matsuo et al. [18], Lowry et al. [19] and Sokolova [20].

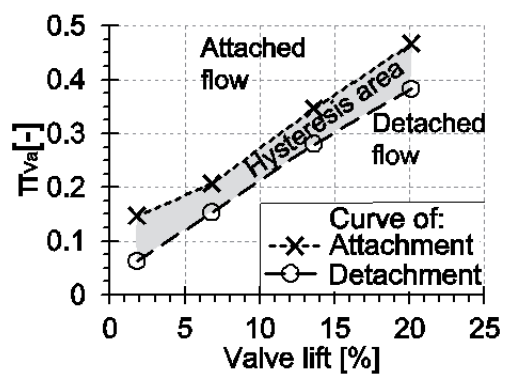

Fig. 8 Curve of attachment and detachment for the base line diffuser

In these experiments a jet formed in a gap with the height $\mathrm{h}$ is accelerated by the pressure ratio $\pi_{\mathrm{Co}}$ and flows along a curved surface with the radius $r$. According to Fig. 9 the same geometric parameters can be taken from the valve geometry. The gap height $\mathrm{h}$ depends on the valve lift. $\mathrm{r}$ is the radius of curvature at the valve seat. The local pressure $\pi_{\mathrm{Co}}$ determining the wall jet separations is defined in Eq. (3).

$$
\pi_{\mathrm{Co}}=\frac{p_{1}}{p_{t, \text { in }}}
$$



Fig. 9 Definition of geometric parameters for the Coanda jet

In Figure 10 the local pressure ratio of attachment $\pi_{\mathrm{Co}}$ from the CFD calculation is drawn versus the radius to height ratio $\mathrm{r} / \mathrm{h}$. Obviously, the CFD results match the experimentally obtained results very good. Hence, the attachment of the wall jet in the steam valve can be referred to the attachment of the basic Coanda flow.

Comparing the pressure ratio of detachment to the experimental results in Fig. 11 gives a small difference between the numerical and experimental results. Nevertheless, the shape of the trend is reproduced. 


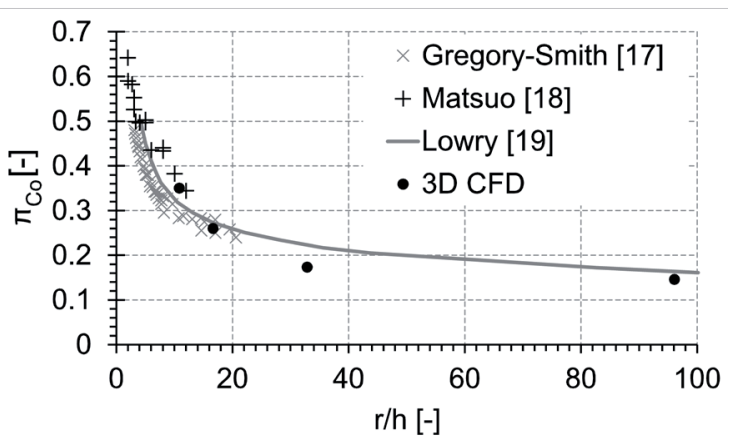

Fig. 10 Comparison of the calculated pressure ratio of attachment to experimental data.

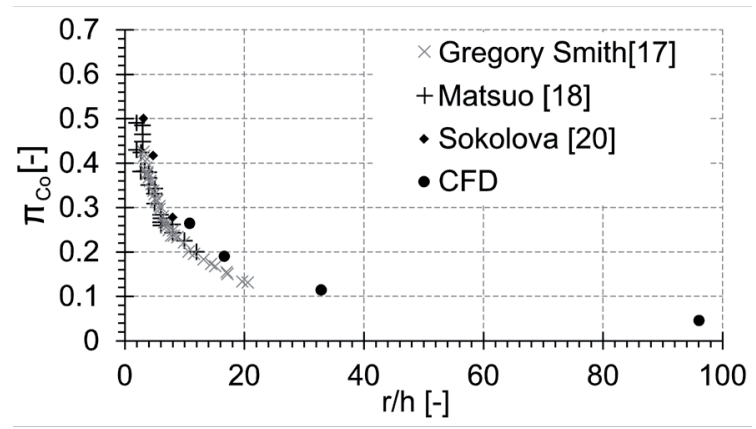

Fig. 11 Comparison of the calculated pressure ratio of detachment to experiments

\section{Modification of the diffuser shape}

The finding, that the pressure ratio of attachment in the steam valve is related to the basic Coanda flow shows a way for the modification of the steam valve diffuser. If the curvature of the valve seat is increased, the geometric $\mathrm{r} / \mathrm{h}$-ratio increases as well. Hence, the results of Figs. 10 and 11 forecast, that the pressure ratio of attachment will decrease for a given valve lift.

\subsection{Design constraints for diffuser shape modification}

Several constraints arising from the mechanical characteristics of the valve have to be considered during the modification process. The geometric parameters are given in Fig. 12.

- The diameter $D_{\mathrm{P}}$ of the valve plug and the outlet diameter $D_{\text {out }}$ must not be changed to avoid a major redesign.

- The position and the diameter $\left(D_{\mathrm{C}}\right)$ of the contact circle (Position A in Fig. 12) formed by the plug and the seat must not be changed.

- The angle $\alpha$ of the tangent at the contact circle must not be amended to maintain sealing properties and to avoid self-locking effects.

\subsection{Impact of seat curvature on wall jet separation at part load}

Prior to the CFD investigation, a parametric study based on an analytical approach is performed to investigate the effect of the wall curvature on the wall jet separation. This intermediate step is performed as the prediction gives immediately results while the CFD analysis needs at least one week on a modern computer workstation. The analytic approach uses the pressure recovery predicted by the CFD and the pressure ratio of attachment known from the experiments shown in Fig. 10. The radius of curvature, defined in Fig. 9, is varied according to the geometric constraints given in Section 4.1. The results are shown in Fig. 13. The radius is normalized by the radius of the baseline design.

It can be seen, that the operational range, in which the flow is attached is extended to lower valve lifts for increased radii. The point of intersection between the operating curve of the valve and the curve of attachment is shifted to lower valve lifts and lower pressure ratios.

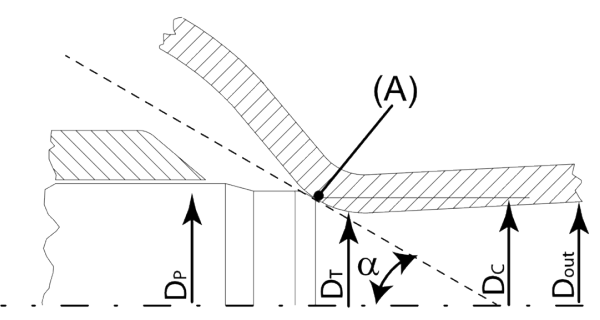

Fig. 12 Geometric design constraints

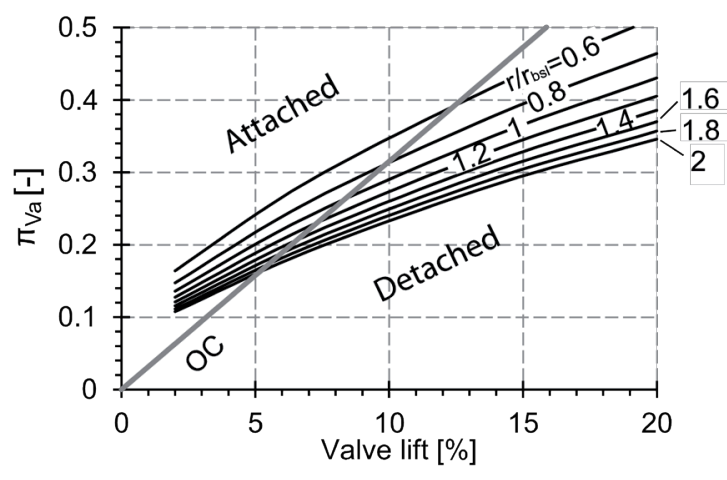

Fig. 13 Curves of attachment calculated for different seat radii. (analytical study)

The transition from attached flow to detached flow on the operational curve (OC) versus the radius of curvature is shown in Fig. 14. For small radii the enlargement of the radius has a strong effect on the flow transition; for large radii the influence is significantly smaller.

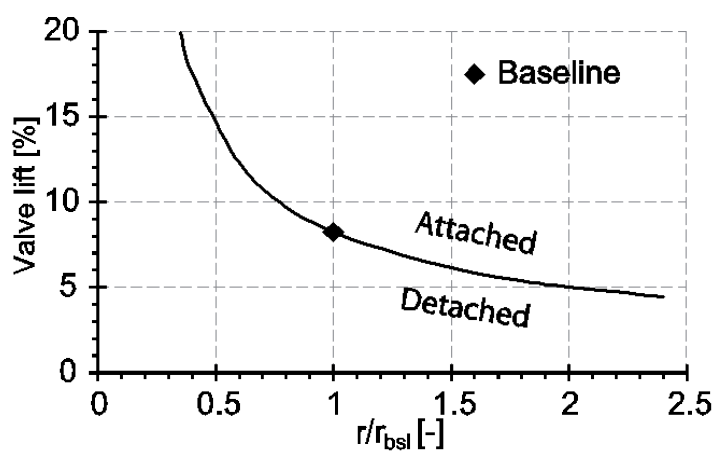

Fig. 14 Dependency of the flow transition on the radius of curvature 
As the design constrains have to be maintained, the throat diameter $D_{T}$ becomes smaller when the radius of curvature is increased. Additionally, the length of the diffuser is increased if a classical conical shape is used. This relation is depicted in Fig. 15. According to calculations conducted by Biancini et al. [16], the pressure losses at full valve lift are expected to increase if the throat diameter of a valve diffuser is reduced. Hence, this point is investigated in the next section.

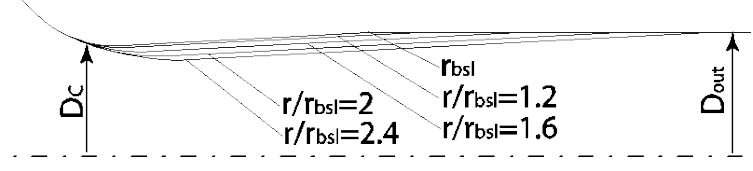

Fig. 15 Diffuser contours obtained with different seat radii

\subsection{Impact of wall curvature on the pressure loss at full valve lift}

The influence of the diffuser design on the pressure losses is analysed. At first the diffuser shape is modified and later in this section the influence of different radii of seat curvature on the pressure loss is investigated using the amended design. As pressure losses are solely relevant at full opened operation of the valve, CFD calculations are performed for this case.

The baseline design of the valve diffuser has a straight, conical diffuser. As the length of the diffuser must not be increased, the pressure losses cannot be reduced by decreasing the opening angle. Hence, the use of a bell shaped curvature is one way to reduce the flow losses under these constraints. An optimal shape of the diffuser design is found by an iterative, manually conducted optimization process. The length of the optimized geometry shown in Fig. 16 versus the straight contour of the baseline design does not exceed the length of the baseline geometry for seat radii smaller than 1.6.



Fig. 16 Contours of the curved diffuser for different seat radii

The pressure losses are reduced by $4.5 \%$ for the improved curved diffuser with the baseline radius. In the next step, the curved diffuser is transferred to valve geometries with an increased seat radius. The influence of the radius of curvature on the pressure loss is depicted in Fig. 17 showing the total pressure loss referenced by the total pressure loss of the baseline design. The total pressure loss increases with increasing curvature of the valve seat. As the curved diffuser design has a lower loss than the conical diffuser design, the radius of curvature can be increased up to $160 \%$ without exceeding the pressure loss of the baseline design. For higher radius ratios the pressure losses increase significantly.

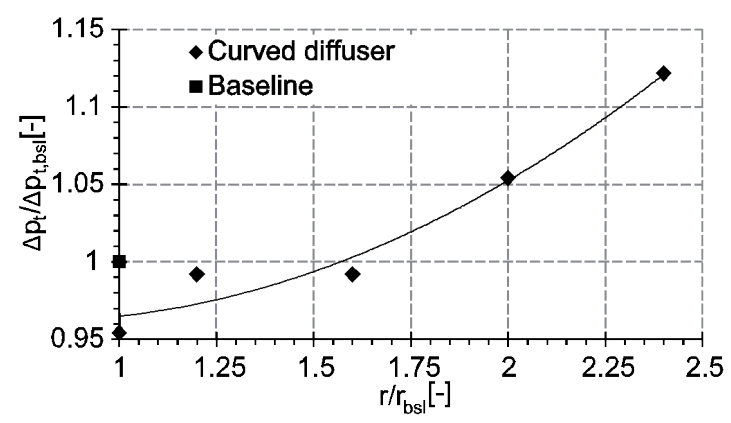

Fig. 17 Total pressure loss in dependency of the radius of curvature. (100\% valve lift)

\subsection{Numerical investigation on the impact of the modified wall curvature}

According to the previous results, the radius of curvature at the valve seat can be enlarged by $60 \%$ without increasing the pressure loss compared to the baseline design of the diffuser. CFD-calculations are performed to determine the pressure ratio of attachment for this geometry with the enlarged radius. The results are depicted in Fig. 18, showing that the operational range without flow separations is increased and the intersection point with the operational curve (OC) is shifted to smaller valve lifts.

This finding basically agrees to the calculation with the analytical 1D-prediction (pre). The absolute value of the transition point from the attached to the detached flow differs between the CFD results and the analytical prediction. But the improvement predicted by both methods agrees well.

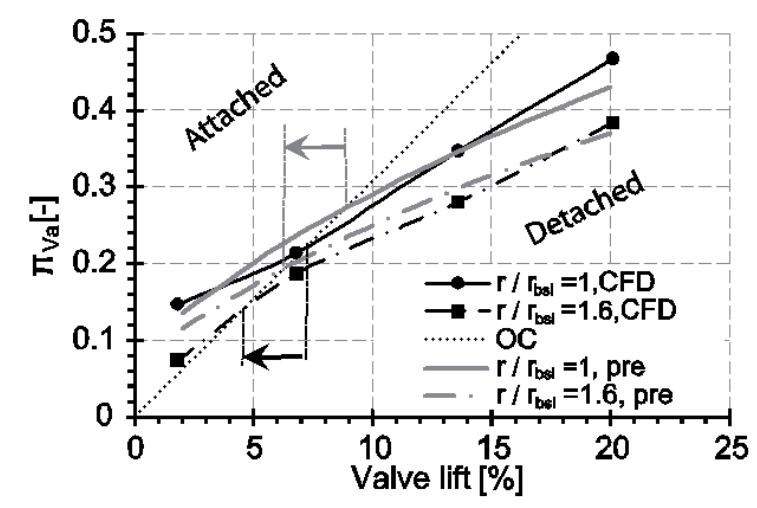

Fig. 18 Results of the CFD calculation

\section{Modification of the plug edge}

As the detachment of Coanda wall jets is related to the shock caused by the recompression in the under expanded supersonic jet, the attachment of the supersonic jet can be improved by a convergent-divergent gap design (CD-gap). In the divergent part of the gap a controlled expansion occurs. As the controlled expansion reduces the pressure at the outlet of the gap, the expansion and the recompression downstream the 
gap is weaker. Hence, shocks are less intense and the attachment of the jet is improved. Experimental investigations by Sokolova [20] and Cornelius and Lucius [21] showing that convergent divergent gaps improve the attachment of supersonic wall jets confirm this theoretical consideration.

A CD-gap can be obtained by reducing the tip diameter of the valve plug according to Fig. 19. In the CD design the cross sectional area at the exit $\mathrm{A}_{\mathrm{EX}}$ is larger than the smallest cross section $\mathrm{A}_{\mathrm{T}}$ forming the throat of the gap.

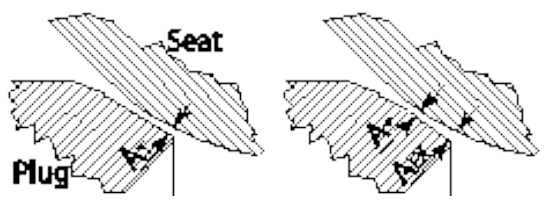

Fig. 19 Different valve gaps

In the baseline design the valve gap has a pure convergent shape. To investigate the effect of the valve gap on the wall jet separation, CFD calculations are performed. The CD gap is obtained by reducing the tip diameter of the valve plug by $0.36 \%$. By this modification a convergent valve gap exist up to $20 \%$ valve lift. The tip of the valve plug has to be designed very carefuly, as convergent divergent gaps with too large divergent sections can produce over expanded jets or even a vertical compression shock in the valve gap. Vertical compression shocks in the valve gap are undesired according to Pluviose [4], as they can generate strong vibrations. The plug investigated here is designed to avoid these undesired phenomena in the typical operational range. For small lifts, at which the pressure ratio is too small to form vertical compression shocks, the gap is convergent-divergent. At medium lifts, at which pressure ratios suitable for the formation of a shock exist, the gap is pure convergent. Hence, the shock is avoided by this plug design.

The results of the CFD calculation depicted in Fig. 20 show that the curve of attachment is shifted to lower pressure ratios for small valve lifts. Hence, the intersection with the operating curve (OC) of the valve is moved to lower lifts and pressure ratios, and the operational range in which the separations occur is reduced. As the throat diameter of the valve is not affected, this way to improve the wall attachment does not influence the pressure loss at the open valve position.

\section{Conclusions}

The transition from the detached to the attached flow in steam valves is related to the attachment of supersonic Coanda wall jets. In case of the detached flow, the vibrations are higher.

The attachment of the jet can be improved by two methods. The radius of the valve seat can be increased to decrease the pressure ratio of attachment or the attachment can be improved by a convergent-divergent valve gap reducing the strength of the expansion.

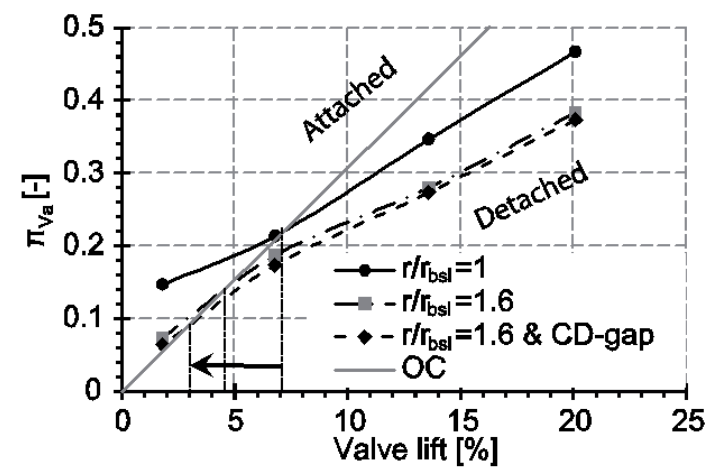

Fig. 20 Curve of attachment of the baseline design and the improved designs (CFD)

The use of curved diffusers can compensate the increased pressure losses and the increased length which come along with increased seat radii. A very large increase of the radius of curvature gives only a small additional improvement of the jet attachment while the pressure losses increase significantly compared to a moderately increased radius.

\section{Acknowledgements}

This work is conducted as a part of the joint research program COOREFLEX-Turbo in the frame of AG Turbo. The work is supported by the German Federal Ministry for Economic Affairs and Energy under grant number 03ET7020A. The authors gratefully acknowledge Siemens AG for their support and permission to publish this paper. The responsibility for the content lies solely with the authors.

\section{Nomenclature}

$\begin{array}{lll}A_{\mathrm{EX}} & {[-]} & \text { area at the exit of the valve gap } \\ A_{\mathrm{T}} & {[-]} & \text { area at the throat of the valve gap } \\ D_{\mathrm{C}} & {[-]} & \text { diameter of the contact circle } \\ D_{\mathrm{P}} & {[-]} & \text { diameter of the valve plug } \\ D_{\mathrm{T}} & {[-]} & \text { diameter of the valve throat } \\ M a & {[-]} & \text { Mach number } \\ a & {[-]} & \text { acceleration } \\ h & {[\mathrm{~m}]} & \text { height of the wall jet } \\ p & {[\mathrm{bar}]} & \text { pressure } \\ p_{\mathrm{t}} & {[\mathrm{bar}]} & \text { total pressure } \\ p_{1} & {[\mathrm{bar}]} & \text { pressure near the wall jet } \\ r & {[\mathrm{~m}]} & \text { radius of curvature } \\ u & {[\mathrm{~m} / \mathrm{s}]} & \text { velocity } \\ y & {[\mathrm{~m}]} & \text { wall distance } \\ y+ & {[-]} & \text { non dimensional wall distance } \\ \Delta p_{\mathrm{t}} & {[\mathrm{bar}]} & \text { total pressure loss } \\ \alpha & {\left[{ }^{\circ}\right]} & \text { angle at contact circle } \\ \omega & {[1 / \mathrm{s}]} & \text { turbulent frequency } \\ \pi_{\mathrm{Co}} & {[-]} & \text { pressure ratio of the coanda jet } \\ \pi_{\mathrm{Va}} & {[-]} & \text { overall pressure ratio of the valve }\end{array}$




\section{Subscripts and Superscripts}

att attachment

bsl baseline

det detachment

in inlet

max maximum

out outlet

pre analytical prediction

ref reference

\section{Abbreviations}

$\mathrm{CD}$ convergent-divergent

OC operating curve

\section{References}

[1] Tecza, J., Chochua, G., Moll, R. "Analysis of Fluid-Structure interaction in a Steam Turbine Throttle Valve." Proceedings of ASME Turbo Expo 2010. GT2010-23788, pp. 2329-2338. 2010. DOI: 10.1115/gt2010-23788

[2] Zhang, D., Engeda, A., Hardin, J. R., Aungier, R. H. "Experimental study of steam turbine control valves." Proceedings of the Institution of Mechanical Engineers, Part C: Journal of Mechanical Engineering Science. 218(5), pp. 493-507. 2004. DOI: 10.1243/095440604323052283

[3] Michaud, S., Ziada, S., Pastorel, H. "Acoustic Fatigue of a Steam Dump Pipe System Excited by Valve Noise." Journal of Pressure Vessel Technology. 123(4), pp. 461-468. 2001. DOI: 10.1115/1.1400741

[4] Pluviose, M. "Stabilization of Flow through Steam-Turbine Control Valves." Journal of Engineering for Gas Turbines and Power. 111(4), pp. 642-646. 1989. DOI: 10.1115/1.3240305

[5] Ziada, S., Bühlmann, E. T., Bolletter, U. "Flow Impingement as an Excitation Source in Control Valves." Journal of Fluids and Structures. 3(5), pp. 529-549. 1989. DOI: 10.1016/s0889-9746(89)80029-5

[6] Nakano, M., Outa, E., Tajima, K. "Noise and Vibration Related to the Patterns of Supersonic Annular Flow in a Pressure Reducing Gas Valve." Journal of Fluids Engineering. 110(1), pp. 55-61. 1988.

DOI: $10.1115 / 1.3243511$

[7] Stastny, M., Bednar, L., Tajc, L., Kolar, P., Martinu, P., Matas, R. "Pulsating Flows in the Inlet of a Nuclear Steam Turbine." In: 5th European Conference on Turbomachinery. Prague, Czech Republic, March 17-22, 2003, pp. 667-686.

[8] Morita, R., Inada, F., Mori, M., Tezuka, K., Tsujimoto, Y. "Flow Induced Vibration of a Steam Control Valve in middle opening condition." Proceedings of PVP2005 ASME Pressure Vessels and Piping Division Conference. pp. 485-490. 2005. DOI: 10.1115/pvp2005-71334

[9] Schramm, A., Muller, T., Polklas, T., Brunn, O., Mailach, R. "Unsteady Flow in Extraction Modules of Industrial Steam Turbines." Proceedings of ASME Turbo Expo 2014. Dusseldorf, Germany, June 16-19, 2014, GT-2014-25394. DOI: 10.1115/gt2014-25394
[10] Domnick, C., Benra, F-K., Dohmen, H. J., Musch, C. "Numerical Investigation on Under Expanded Wall Jet Separation in a Steam Turbine Valve Diffuser." International Symposium on rotating machinery ISROMAC-15, Honolulu, USA, February 27-28, 2014. Paper No. TU-305.

[11] Domnick, C., Benra, F-K., Dohmen, H. J., Musch, C. "Numerical Investigation on the Time-Variant Flow Field and the Dynamic Forces Acting in Steam Turbine Inlet Valves." Journal of Engineering for Gas Turbines and Power. 137(8), pp. 081601-081601-11. 2015.

DOI: $10.1115 / 1.4029309$

[12] Domnick, C. B., Benra, F.-K., Brillert, D., Musch, C. "Modification of a steam valve diffuser for enhanced full load and part load operation using numerical methods." Conference on modeling fluid flow, CMFF15. Budapest, Hungary, September 1-4, 2005. Paper No. 41.

[13] Wagner, W., Cooper, J. R., Dittmann, A., Kijima, J., Kretzschmar, H.J., Kruse, A., Mares, R., Oguchi, R., Sato, H., Stöcker, I., Sifner, O., Takaishi, Y., Tanishita, I., Trübenbach J., Willkommen, Th. "The IAPWS Industrial Formulation 1997 for the Thermodynamic Properties of Water and Steam." Journal of Engineering for Gas Turbines and Power. 122(1), pp. 150-182. DOI: 10.1115/1.483186

[14] Menter, F. R. "Two-Equation Eddy-Viscosity Turbulence Models for Engineering Applications." AIAA Journal. 32(8), pp. 1598-1605. 1994. DOI: $10.2514 / 3.12149$

[15] Clari, M. "Untersuchung von instationären Strömungsablösungen in den Diffusoren von Regelungsventilen von Dampfturbinen." (Investigation on flow separations in steam turbine control valves.) Doctoral thesis, Helmut-Schmidt-Universität, Hamburg, Germany, 2014. (in German) URN: urn:nbn:de:gbv:705-opus-30797 URL: http://edoc.sub.uni-hamburg.de/hsu/volltexte/2014/3079/

[16] Bianchini, C., Micio, M., Tarchi, L., Cortese, C., Imparto, E., Tampucci, D. "Numerical Analysis of Pressure Losses in Diffuser and Tube Steam Partition Valves." Proceedings of ASME Turbo Expo 2013. San Antonio, Texas, June 3-7, 2013. GT2013-95527. DOI: 10.1115/gt2013-95527

[17] Gregory-Smith, D. G., Gilchrist, A. R. "The compressible Coanda wall jet - an experimental study of jet structure and breakaway." International Journal of Heat and Fluid Flow. 8(2), pp. 156-164. 1987. DOI: $10.1016 / 0142-727 \times(87) 90019-1$

[18] Matsuo, S., Setoguchi, T., Kudo, T., Yu, S. "Study on the Characteristics of Supersonic Coanda jets." Journal of Thermal Sciences. 7(3), pp. 165175. 1998. DOI: $10.1007 / \mathrm{s} 11630-998-0012-2$

[19] Lowry, J. G., Riebe, J. M., Campbell, J. P. "The Jet-Augmented Flap." Institute of the Aeronautical Sciences Paper. 715. 1957.

[20] Sokolova, I. N. "Investigation of Supersonic Coanda Flow." Fluid Mechanics-Soviet Research. 15, pp. 1-6. 1986.

[21] Cornelius, K. C., Lucius, G. A. "Physics of Coanda Jet Detachment at High-Pressure Ratio." Journal of Aircraft. 31(3), pp. 591-596. 1994. DOI: $10.2514 / 3.46535$ 